\title{
English Reform in Medical Colleges Based on ESP Theory
}

\author{
Wang Lu \\ Qiqihar Medical University
}

Keywords: English reform; ESP; medical colleges

\begin{abstract}
ESP course teaching materials are basically chosen from the original materials, terminology, concepts, and process description, etc. Due to cultural differences and reasons in the difference of thinking, they often make students understand and master a validation. Sometimes the professor who spends plenty of time to explain and illustrate will deviate from the topic which not only affects the teaching effect and atmosphere, but the teaching organization of lecturers and consistency of the ideas and content as well. Thus, an effective and beneficial ESP designing method will be more important during the ESP English learning and teaching. In order to make ESP theory and practice in medical schools more reasonable and applicable, English teachers and ESP practitioners need to reform the English curriculum in medical colleges based on ESP theory.
\end{abstract}

\section{Introduction}

ESP is an emerging branch of science that was formed in the 1960s. Specialized English is a type of English that is associated with a particular profession, subject or purpose. It has two distinct characteristics: first, the user has a clear scope of use. Because of the needs of a particular industry, the user must use the language in his field of work. Second, it has special language contents, that is, specialized contents. English for General Purposes (EGP) is the foundation of specialized English (ESP), and ESP is necessary for the development of General English. From the perspective of students' learning process, the transition from ordinary English to specialized English is an inevitable progression.

The basic task of ESP is to enable students to complete the teaching and scientific research of a subject in English and to practice application in the work so as to successfully carry out academic exchange and complete business operation. As a result, it can be concluded that the learners and users of ordinary English must be specially trained, studied and learned before mastering and applying the English language of special purpose.

\section{Investigation and Development of ESP in China and abroad}

At present, ESP teaching and researching abroad has made great progress and fruitful results. In the British and American countries, particularly, ESP has formed a relatively complete system including vocational English, traveling English, hotel English, medical English, etc., as well as English for Academic use (EAP).

However, the teaching and researching of ESP in China is a process of continuous exploration, and the definition of ESP in China is not very clear and fixed. Therefore, how to deepen the study of the language and teaching theory of special-purpose English is an important and arduous task which the English teaching workers are facing in our country.

\section{Reform of English Courses in Higher Medical Institutions}

Along with the rapid development of medicine and the International connection in China's education, healthcare, and other causes, we, as a medical worker, can only be familiar with the medical English to better study the foreign advanced medical theory and technology, to promote the rapid development of our country's medicine enterprise. For example, most of the latest advances and results in medicine are published in English in international journals or at international 
conferences. To timely grasp the international medical and scientific research dynamic, it is necessary to view the latest medical English literatures, to participate in the international medical exchanges and so on. All of these are requiring medical workers to be equipped with skillful English for special purposes, which will make English, as its professional services, beneficial to the future work, and can meet the demand of their language learning more than English linguistics and English language and literature. Consequently, it is necessary to establish a model among English subjects with the goal of "professional language" in medical colleges. ESP should replace EGP as the center of English teaching in medical colleges.

The common problems in the English curriculum for specialized purposes in most medical schools:

1) The setting of curriculums is incomplete.

2) There is no continuity in curriculum setting.

3) There is no definite correlation between the courses.

4)There is a great discrepancy between the curriculum and student demand.

5) There is an uneven distribution of professional English courses.

One of the biggest problems is the mismatch between curriculum and student's demand. Language teachers focus on English and language knowledge, while students focus on professional knowledge. They fundamentally confuse the difference between specialized English courses and bilingual courses. Another reason that affected the quality of English teaching at the same time can not to be ignored. In general, the first and second grade is relatively stable, and they have a readymade compile material, a clear teaching purpose, a unified teaching plan and arrangement for universal use. Teachers are relatively easier to operate. Instead, a series of problems about elective courses after grade three will appear, such as no compiled materials and clear syllabus for universal use in teaching. Teachers can't unity in the process of teaching among various curriculums, let alone to cooperate with each other, so they won't be able to do supplement and promote each other in the course.

English for special purpose is not to teach a special kind of English. Although it has its special linguistic features, it does not have a special category of language. In terms of teaching principles and teaching process, there is no essential difference between special-purpose English teaching and general English teaching. On the other hand, there are differences between them. First of all, according to different learners and learning phases, the teaching purposes of both are different. General English teaching is a basic English skill for cultivating learners' listening, speaking, reading, writing and translating. English teaching for special purposes is to guide students to read relevant professional English books and periodicals, so as to enable them to further read and translate English scientific and technological information, and to acquire the information required by English as a tool. From this perspective, general English teaching is a prerequisite for the use of English teaching, while the special purpose English teaching is the advanced stage of general English teaching. ESP plays an equally important role in language teaching with general English. Therefore, ESP teaching is a branch of English language teaching with all the characteristics and requirements of language teaching.

The practice and research of ESP design at home and abroad have been discussed a lot. The two kinds of ESP designing methods commonly used abroad are domain analysis and discourse analysis. The former is established on the basis of traditional grammar designing method, and its theoretical core is: language vocabulary, grammar and format in different social environment, such as the different language domain can have unique characteristics, register to language environment and the connotation of the language, thus find out the register and the analysis is an effective method to explore the rule ESP language expression.

Based on the combination of the first two foreign teaching methods, ESP teaching in China inevitably uses the grammar-translation method which is used in the medium and long term of professional English teaching. Although this method has its limitation, it is not useless, and it is the necessary means and necessary stage of ESP teaching in non-English speaking countries. 


\section{Conclusion}

ESP course teaching materials are basically chosen from the original materials, terminology, concepts, and process description, etc. Due to cultural differences and reasons in the difference of thinking, they often make students understand and master a validation. Sometimes the professor who spends plenty of time to explain and illustrate will deviate from the topic which not only affects the teaching effect and atmosphere, but the teaching organization of lecturers and consistency of the ideas and content as well. Thus, an effective and beneficial ESP designing method will be more important during the ESP English learning and teaching. In order to make ESP theory and practice in medical schools more reasonable and applicable, we as English teachers and ESP practitioners need to reform the English curriculum in medical colleges based on ESP theory.

\section{Acknowledgements}

Fund project: The basic theory project of philosophy and social science in Qiqihar City "Training Mode Research of Writing Ability Among Medical Staffs Based on ESP Theory” (QSX2017-24JL).

\section{Reverences}

[1] Lv Gui. Some implications of Japanese medical English education on medical English teaching in Chinese higher medical institutions [J]. Northwest Medical Education. 2008(04)

[2] Zhang Yan, Wu Xinwei, Zhang Shunxing. Investigation and Analysis of the Current Situation of Medical English Teaching in Chinese Higher Medical Institutions [J]. Chinese Higher Medical Education. 2006 (08)

[3] Qin Xiubai. The Nature, Category and Teaching Principles of ESP -- A Discussion on The Feasibility of Teaching Various Types of English Teaching in Chinese Universities [J]. Journal of South China University of Technology (Social Science Edition). 2003(04) 